\title{
Living Conditions and Helicobacter pylori in Adults
}

\author{
Odete Amaral, ${ }^{1}$ Isabel Fernandes, ${ }^{1}$ Nélio Veiga, ${ }^{2,3}$ Carlos Pereira, ${ }^{1}$ \\ Claudia Chaves, ${ }^{1}$ Paula Nelas, ${ }^{1}$ and Daniel Silva ${ }^{1}$ \\ ${ }^{1}$ CIßDETS, Polytechnic Institute of Viseu, Viseu, Portugal \\ ${ }^{2}$ Health Sciences Institute, Universidade Católica Portuguesa, Lisbon, Portugal \\ ${ }^{3}$ Centre for Interdisciplinary Research in Health (CIIS), Universidade Católica Portuguesa, Lisbon, Portugal
}

Correspondence should be addressed to Nélio Veiga; nelioveiga@gmail.com

Received 6 July 2017; Revised 3 September 2017; Accepted 12 September 2017; Published 12 October 2017

Academic Editor: Dimitrios P. Bogdanos

Copyright (C) 2017 Odete Amaral et al. This is an open access article distributed under the Creative Commons Attribution License, which permits unrestricted use, distribution, and reproduction in any medium, provided the original work is properly cited.

\begin{abstract}
Introduction. Infection by the bacterium Helicobacter pylori (H. pylori) is transmissible and is considered a public health issue which affects people of all ages. The objective of this study was to identify factors (lifestyles, dietary factors, and hygiene conditions) related to the prevalence of $H$. pylori infection. Methods. We carried out an observational cross-sectional study with a community sample of adults from the municipalities of Viseu and Sátão, Portugal. The final sample resulted in 166 adults. The data were collected through a self-administered questionnaire with questions regarding sociodemographic aspects and lifestyles. $H$. pylori infection was identified using the 13C-urea breath test. Results. No association was found between the prevalence of $H$. pylori infection and the use of tobacco, alcohol, or coffee or dietary factors. The prevalence of $H$. pylori infection was higher in adults who reported higher consumption of fried food and lower consumption of vegetables and fruit. $H$. pylori infection was significant for the variables of lower frequency of handwashing before going to the bathroom $(p=0.02)$ and well water consumption $(p=0.05)$. Conclusion. A significant association was found for $H$. pylori infection with the lower frequency of handwashing before going to the bathroom and the consumption of well water.
\end{abstract}

\section{Introduction}

H. pylori is considered to be a chronic and transmissible infection, even though the exact chain of transmission is not completely known. It is believed that human beings are practically the only natural reservoir of $H$. pylori [1]. Research suggests that contact with the bacterium occurs predominantly during childhood and between direct family members (intrafamilial transmission) [2, 3]. Intrafamilial transmission appears to be the main route for the acquisition of this infection, especially among mothers and children and among siblings, supporting the hypothesis that close contact is crucial for the transmission of the infection $[4,5]$. In developing countries, studies report that the hygiene conditions and the surrounding environment influence the transmission of $H$. pylori $[6,7]$. Person-to-person transmission through oral-tooral or fecal-to-oral routes is considered the most probable, and this pathogen can be transmitted orally through fecal matter by the ingestion of water contaminated with waste [1]. Risk factors related to $H$. pylori infection include poor socioeconomic status, poor hygiene, inadequate sanitation conditions, overcrowding, consumption of contaminated water and food, and bacterial infection within the household $[1,8]$. The improvement of hygiene standards, mainly due to the implementation of basic sanitation, a decrease in the number of close contacts, and, possibly, an increase in the consumption of antibiotics, contributed to a gradual variation in the frequency of infection in the different phases of the life cycle. In other words, this infection now has a higher incidence in the later stages of childhood, adolescence, and adulthood [4,9]. Therefore, the identification of the determinants of $H$. pylori infection in different phases of the life cycle is essential to understand its increasing incidence in certain countries and populations, development, and health consequences in the human body.

A study from Brazil reported an increase in $H$. pylori infection associated with a higher number of siblings, schooling since nursery school, and housing with poor conditions and no paved roads, which can be considered important indicators associated with poor living conditions [10]. Poor 
sanitation conditions and overcrowding may also constitute important risk factors for $H$. pylori infection. Likewise, the number of people per room and the number of children in a household were also identified as independent risk factors for H. pylori infection [11]. Another study conducted in Germany indicated a positive association for $H$. pylori infection with "more than three children living in the household" $(\mathrm{OR}=2.4$; $p=0.001)$, "more people living per square meter above the average" $(\mathrm{OR}=1.4 ; p=0.03)$, "the house being located on the main road" ( $\mathrm{OR}=1.4 ; p=0.04)$, and "consumption of well water" $(\mathrm{OR}=2.3 ; p=0.05)$ [12]. However, the functional components of many other associated factors are not fully clarified.

Accordingly, the objective of this study was to identify factors (lifestyles, dietary factors, and hygiene conditions) related to the prevalence of $H$. pylori infection.

\section{Participants and Methods}

We carried out an observational epidemiological crosssectional study. The sample consisted of 166 adult individuals from the municipalities of Viseu and Sátão, Portugal. The majority of the sample were female $(56.6 \%)$ with a mean age of $46.96 \pm 3.17$ years (minimum of 19 years old and maximum of 92 years old). The majority of the sample were aged $\leq 50$ years $(54.8 \%)$, were married or lived in a nonmarital relationship (64.5\%), held a bachelor's or a licentiate's degree (35.2\%), and were employed (70.9\%). The exclusion criteria defined for the present study were as follows: the participant was medicated with antibiotics in the past 30 days, ate any kind of food or drank beverages in the last 6 hours, and underwent any kind of eradication treatment before or at the time of the 13C-urea breath test, in order to avoid the presence of fake negatives in the present study.

We collected the data through a self-administered questionnaire divided into three main sections: (I) sociodemographic variables (gender, age, marital status, residence area, scholarship, professional situation, and crowding index) with a total of 10 questions; (II) clinical situation (diseases and other health outcomes and daily medication) with a total of 6 questions; (III) household composition and lifestyles (dietary factors, tobacco and coffee consumption, physical exercise, hygiene practices, and household conditions) with a total of 12 questions.

In order to assess the presence of $H$. pylori, we used the 13C-urea breath test, which is considered a noninvasive test and of easy application in community observational epidemiological studies. The test was performed in the morning at the home of the participant and in the presence of the main researcher, after at least 6 hours of fasting by the participant. The protocol consisted in the exhalation of carbon dioxide in samples before and after swallowing urea labeled with nonradioactive carbon-13. The samples were then analyzed and each result would be classified as positive or negative for H. pylori infection.

The study was submitted and approved by the Ethics Committee of the Education School of Health of the Polytechnic Institute of Viseu, Portugal. The data collection instrument was voluntarily answered by adults, and the confidentiality and anonymity of the information collected were guaranteed.

After collecting the data, the questionnaires were numbered, stored, and processed, using the Statistical Package for the Social Sciences (SPSS version 23.0). The prevalence was expressed in proportions and the odds ratio (OR) with a 95\% confidence interval (CI) was used to measure the strength of the association between variables. Proportions were compared by the chi-square test. The level of significance was set at $5 \%(p<0.05)$.

\section{Results}

The prevalence of $H$. pylori was $48.8 \%$, higher in females (50.0\% versus $47.2 \%, p=0.72)$, in individuals over 40 years of age $(51.8 \%$ versus $42.9, p=0.27)$, in individuals with lower academic qualifications $(\leq 12$ th grade $53.3 \%$ versus $>12$ th grade $43.8 \%, p=0.23$ ), and in adults who reported having two or more siblings (53.8\% versus $42.7 \%, p=0.15$ ), but with no statistical differences for the sociodemographic variables.

Regarding the lifestyle and the presence of $H$. pylori, Table 1 shows that there was no association between the prevalence of $H$. pylori infection and the use of tobacco, alcohol, or coffee. The prevalence of $H$. pylori infection is higher in individuals who do not drink alcohol, do not smoke, and do not drink coffee. Nevertheless, no statistically significant association was found. Also, among adults who drink coffee, the prevalence for $H$. pylori infection is higher in those who report drinking 2 or more coffees a day, without any significant differences.

The results in Table 2 suggest that the $H$. pylori infection was higher for individuals who reported that they had never eaten or would rarely eat fried food, when compared to adults who reported eating fried food at times or almost every day $(\mathrm{OR}=1.04,95 \% \mathrm{CI}: 0.56-1.92)$. It increased for individuals who ate vegetables less frequently $(50.0 \%)$ in comparison to those who ate them almost every day or every single day (48.8\%, $p=0.84)$. In contrast, the prevalence of $H$. pylori was higher in people who did not drink milk (55.2\% versus $47.4 \% ; p=0.45)$ and in adults who reported drinking soft drinks ( $\mathrm{OR}=1.33$, 95\% CI: 0.71-2.49). However, we did not find any dietary factor with a significant association with $H$. pylori infection.

Most people reported having piped water $(n=162$; $97.6 \%)$, but 4 people (2.4\%) reported not having piped water. In relation to the sewage system, most of the sample reported that they have a sewage network linked to their household ( $n=159,95.8 \%$ versus $n=7,4.2 \%)$.

When we analyzed the relation between the prevalence of $H$. pylori infection and hygiene conditions (Table 3 ), we found that individuals who mentioned having washed their hands before going to the bathroom rarely or sometimes had a lower risk than those who had never done this $(\mathrm{OR}=0.40$, 95\% CI: $0.18-0.87)$. Also, the consumption of well water is positively related to $H$. pylori infection $(\mathrm{OR}=2.13,95 \% \mathrm{CI}$ : $1.00-4.64)$, although the statistical association is marginal. In relation to all the other variables analyzed, we did not find any statistically significant differences. 
TABLE 1: Relationships between the prevalence of $H$. pylori infection and lifestyles.

\begin{tabular}{|c|c|c|c|c|c|c|}
\hline & H. pylori positive & H. pylori negative & Total & Prevalence of $H$. pylori (\%) & OR (95\% CI) & $p$ \\
\hline \multicolumn{7}{|c|}{ Alcohol consumption } \\
\hline Yes & 22 & 31 & 53 & 41.5 & $0.65(0.34-1.26)$ & \multirow{2}{*}{0.20} \\
\hline No & 59 & 54 & 113 & 52.2 & $1^{*}$ & \\
\hline \multicolumn{7}{|c|}{ Tobacco consumption } \\
\hline Yes & 20 & 31 & 51 & 39.2 & $0.57(0.29-1.12)$ & \multirow{2}{*}{0.10} \\
\hline No & 61 & 54 & 115 & 53.0 & $1^{*}$ & \\
\hline \multicolumn{7}{|c|}{ Number of cigarettes per day } \\
\hline$\leq 10$ cigarettes & 14 & 19 & 33 & 42.4 & $1.33(0.36-4.83)$ & \multirow{2}{*}{0.67} \\
\hline$>10$ cigarettes & 5 & 9 & 14 & 35.7 & $1^{*}$ & \\
\hline \multicolumn{7}{|c|}{ Coffee consumption } \\
\hline Yes & 56 & 63 & 119 & 47.1 & $0.75(0.40-1.54)$ & \multirow{2}{*}{0.48} \\
\hline No & 25 & 22 & 47 & 53.2 & $1^{*}$ & \\
\hline \multicolumn{7}{|c|}{ Number of coffees per day } \\
\hline 1 & 26 & 36 & 62 & 41.9 & $0.61(0.30-1.30)$ & \multirow{2}{*}{0.21} \\
\hline 2 or more & 28 & 24 & 52 & 53.8 & $1^{*}$ & \\
\hline
\end{tabular}

TABLE 2: Association between the prevalence of $H$. pylori infection and dietary factors.

\begin{tabular}{|c|c|c|c|c|c|c|}
\hline & H. pylori positive & H. pylori negative & Total & Prevalence of $H$. pylori (\%) & OR $(95 \% \mathrm{CI})$ & $p$ \\
\hline \multicolumn{7}{|l|}{ Frequency of eating fried food } \\
\hline Never/rarely & 36 & 37 & 73 & 49.3 & $1.04(0.56-1.92)$ & \multirow{2}{*}{0.91} \\
\hline Sometimes/almost every day & 45 & 48 & 93 & 48.4 & $1^{*}$ & \\
\hline \multicolumn{7}{|l|}{ Frequency of eating vegetables } \\
\hline Rarely/sometimes & 25 & 25 & 50 & 50.0 & $1.07(0.55-2.08)$ & \multirow{2}{*}{0.84} \\
\hline Almost every day/every day & 56 & 60 & 116 & 48.3 & $1^{*}$ & \\
\hline \multicolumn{7}{|l|}{ Frequency of eating fruit } \\
\hline Never/sometimes & 18 & 19 & 37 & 48.6 & $0.99(0.48-2.06)$ & \multirow{2}{*}{0.98} \\
\hline Almost every day/every day & 63 & 66 & 129 & 48.8 & $1^{*}$ & \\
\hline \multicolumn{7}{|l|}{ Consumption of milk } \\
\hline Yes & 65 & 72 & 137 & 47.4 & $0.73(0.33-1.64)$ & \multirow{2}{*}{0.45} \\
\hline No & 16 & 13 & 29 & 55.2 & $1^{*}$ & \\
\hline \multicolumn{7}{|l|}{ Consumption of soft drinks } \\
\hline Yes & 53 & 50 & 103 & 51.5 & $1.33(0.71-2.49)$ & \multirow{2}{*}{0.38} \\
\hline No & 28 & 35 & 63 & 44.4 & $1^{*}$ & \\
\hline
\end{tabular}

\section{Discussion}

In the current study, we intend to identify dietary factors, lifestyles, and hygiene conditions associated with $H$. pylori infection. We did not find any significant differences between $H$. pylori infection and coffee, alcohol, and tobacco consumption. Evidence is also not consensual about the association with these variables [13]. A study carried out in Japan showed that smoking was negatively related to H. pylori infection [14]. Some studies show a positive relationship while others have found no relationship between smoking and $H$. pylori infection $[1,13,14]$. Other studies have shown an association between $H$. pylori infection and tobacco consumption and the number of cigarettes per day (suggesting that the risk of $H$. pylori infection decreased with the daily cigarette consumption) [1]. Regarding alcohol consumption, previous studies have found a relationship between $H$. pylori infection and alcohol consumption, although most of them did not find a significant association $[15,16]$. Interestingly, in a cross-sectional study of 447 adults with a positivity evaluation of $H$. pylori using the $13 \mathrm{C}$-urea breath test, Brenner found a $21 \%$ prevalence of infection and suggested a negative dose-response relation with alcohol consumption (consumption of $>75 \mathrm{~g}$ ethanol/week after adjusting the variables for gender, age, educational level, nationality, and family history of ulcer; $\mathrm{OR}=0.33,95 \%$ CI: $0.16-0.68)$ and a positive dose-response association with coffee consumption (less than 3 coffees; OR $=1.49,95 \%$ CI: $0.71-3.12 ; \geq 3$ coffees; $\mathrm{OR}=2.49,95 \% \mathrm{CI}: 1.23-5.03$ ) [17]. 
TABLE 3: Prevalence of $H$. pylori infection and hygiene conditions $(p<0.05$ represents statistically significant $p$ values obtained in the present study).

\begin{tabular}{|c|c|c|c|c|c|c|}
\hline & $\begin{array}{l}\text { H. pylori } \\
\text { positive }\end{array}$ & $\begin{array}{l}\text { H. pylori } \\
\text { negative }\end{array}$ & Total & $\begin{array}{c}\text { Prevalence of } H \text {. } \\
\text { pylori }(\%)\end{array}$ & OR $(95 \% \mathrm{CI})$ & $p$ \\
\hline \multicolumn{7}{|c|}{$\begin{array}{l}\text { Frequency of washing hands before going to } \\
\text { the bathroom }\end{array}$} \\
\hline Never & 25 & 16 & 41 & 61.0 & $1^{*}$ & \\
\hline Rarely/sometimes & 30 & 48 & 78 & 38.5 & $0.40(0.18-0.87)$ & 0.02 \\
\hline Almost always/always & 26 & 21 & 47 & 55.3 & $0.79(0.34-1.86)$ & 0.59 \\
\hline \multicolumn{7}{|c|}{$\begin{array}{l}\text { Frequency of washing hands after going to the } \\
\text { bathroom }\end{array}$} \\
\hline Never & 6 & 9 & 15 & 40.0 & $1^{*}$ & \\
\hline Rarely/sometimes & 17 & 18 & 35 & 48.6 & $1.42(0.42-4.83)$ & 0.56 \\
\hline Almost always/always & 58 & 58 & 116 & 50.0 & $1.50(0.50-4.49)$ & 0.47 \\
\hline \multicolumn{7}{|c|}{ Frequency of washing hands before meals } \\
\hline Never & 7 & 8 & 15 & 46.7 & $1^{*}$ & \\
\hline Rarely/sometimes & 38 & 34 & 72 & 52.8 & $1.28(0.42-3.90)$ & 0.66 \\
\hline Almost always/always & 36 & 43 & 79 & 45.6 & $0.96(0.32-2.89)$ & 0.94 \\
\hline \multicolumn{7}{|c|}{$\begin{array}{l}\text { Frequency of washing hands before going to } \\
\text { sleep }\end{array}$} \\
\hline Never & 13 & 11 & 24 & 54.2 & $1^{*}$ & \\
\hline Rarely/sometimes & 27 & 33 & 60 & 45.0 & $0.69(0.27-1.79)$ & 0.45 \\
\hline Almost always/always & 41 & 41 & 82 & 50.0 & $0.85(0.34-2.11)$ & 0.72 \\
\hline \multicolumn{7}{|l|}{ Has ever bitten their nails } \\
\hline Yes & 28 & 25 & 53 & 51.5 & $1.27(0.66-2.44)$ & \multirow{2}{*}{0.48} \\
\hline No & 53 & 60 & 113 & 44.4 & $1^{*}$ & \\
\hline \multicolumn{7}{|l|}{ Drinking water } \\
\hline Public network & 24 & 33 & 57 & 42.1 & $0.91(0.44-1.87)$ & 0.79 \\
\hline Well & 29 & 17 & 46 & 63.0 & $2.13(1.00-4.64)$ & 0.05 \\
\hline Bottled & 28 & 35 & 63 & 44.4 & $1^{*}$ & \\
\hline
\end{tabular}

${ }^{*}$ Reference group.

Regarding hygiene conditions, studies have shown an increase in $H$. pylori infection associated with a greater number of siblings and housing in a street with unpaved roads and no sanitary conditions, indicating worse living conditions, the use of well water, and a higher agglomeration index as risk factors $[10,12]$. In this study, we observed a borderline association with well water consumption $(p=$ $0.05)$ and an association with washing hands before going to the bathroom $(p=0.02)$.

With regard to dietary factors and the infection, studies have reported that some dietary risks for gastritis are also considered as risk factors for $H$. pylori $[18,19]$.

Once again, there is evidence that $H$. pylori is associated with the consumption of contaminated water, but not food. It is thought that person-to-person contact is the most likely mode of transmission, and there is no direct evidence that food is involved in the transmission of $H$. pylori [20]. This association between food and $H$. pylori infection will be related not only to the type of diet (healthy, unhealthy), but also especially to the consumption of contaminated food, in which this contamination will be higher when consuming contaminated raw vegetables and fruit. In developing countries, the consumption of drinking water and vegetable products contaminated by sewage can be a serious risk [21]. The consumption of vegetables and fruit, raw and contaminated, (fertilized with feces), was considered a risk factor for infection as well as the consumption of contaminated drinking water [21-23].

\section{Conclusion}

Among the food factors, lifestyles, and hygiene conditions, we found a significant association for $H$. pylori infection with the lower frequency in handwashing before going to the bathroom and the consumption of well water. Additional research should address the relations observed in representative population samples and aim to gain an understanding of their underlying mechanisms. Thus, the identification of the 
determinants of $H$. pylori infection in different phases of the life cycle is essential to understand the association with the different outcomes that can be caused by the infection and, therefore, understand better the influence that it may have in different populations.

\section{Conflicts of Interest}

The authors declare that there are no conflicts of interest regarding the publication of this manuscript.

\section{Acknowledgments}

This study was financed by national funds through Fundação para a Ciência e Tecnologia (FCT), I.P., under the Project UID/Multi/04016/2016. Furthermore, the authors would like to thank the Polytechnic Institute of Viseu and CI\&DETS for their support.

\section{References}

[1] Y. Zhu, X. Zhou, J. Wu, J. Su, and G. Zhang, "Risk factors and prevalence of helicobacter pylori infection in persistent high incidence area of gastric carcinoma in yangzhong city," Gastroenterology Research and Practice, vol. 2014, Article ID 481365, 2014.

[2] S. Schwarz, G. Morelli, B. Kusecek et al., "Horizontal versus familial transmission of Helicobacter pylori," PLoS Pathogens, vol. 4, no. 10, Article ID e1000180, 2008.

[3] J. G. Kusters, A. H. M. van Vliet, and E. J. Kuipers, "Pathogenesis of Helicobacter pylori infection," Clinical Microbiology Reviews, vol. 19, no. 3, pp. 449-490, 2006.

[4] N. Lunet, "A Infeção por Helicobacter pylori numa Região de Alto Risco de Cancro do Estômago," Arquivos de Medicina, vol. 25, no. 5-6, pp. 213-217, 2011.

[5] M. Weyermann, D. Rothenbacher, and H. Brenner, "Acquisition of helicobacter pylori infection in early childhood: Independent contributions of infected mothers, fathers, and siblings," American Journal of Gastroenterology, vol. 104, no. 1, pp. 182-189, 2009.

[6] R. H. Hunt, S. D. Xiao, F. Megraud et al. et al., "Helicobacter pylori in developing countries," World Gastroenterology Organization Global Guidelines, 2010.

[7] L. M. Brown, "Helicobacter pylori: epidemiology and routes of transmission," Epidemiologic Reviews, vol. 22, no. 2, pp. 283-297, 2000.

[8] K. L. Goh, W. K. Chan, S. Shiota, and Y. Yamaoka, "Epidemiology of Helicobacter pylori infection and public health implications," Helicobacter, vol. 16, supplement 1, pp. 1-9, 2011.

[9] M. A. Tkachenko, N. Z. Zhannat, L. V. Erman et al., "Dramatic changes in the prevalence of Helicobacter pylori infection during childhood: A 10-year follow-up study in Russia," Journal of Pediatric Gastroenterology and Nutrition, vol. 45, no. 4, pp. 428-432, 2007.

[10] V. C. C. Dattoli, R. V. Veiga, S. S. Da Cunha, L. C. Pontes-DeCarvalho, M. L. Barreto, and N. M. Alcântara-Neves, "Seroprevalence and potential risk factors for helicobacter pylori infection in Brazilian children," Helicobacter, vol. 15, no. 4, pp. 273-278, 2010.

[11] A. M. N. Fialho, A. B. C. Braga, M. B. Braga Neto et al., "Younger Siblings Play a Major Role in Helicobacter pylori Transmission
Among Children From a Low-Income Community in the Northeast of Brazil," Helicobacter, vol. 15, no. 6, pp. 491-496, 2010.

[12] K. Strebel, U. Rolle-Kampczyk, M. Richter, A. Kindler, T. Richter, and U. Schlink, "A rigorous small area modelling-study for the helicobacter pylori epidemiology," Science of the Total Environment, vol. 408, no. 18, pp. 3931-3942, 2010.

[13] C. Zhong, K.-N. Li, J.-W. Bi, and B.-C. Wang, "Sodium intake, salt taste and gastric cancer risk according to helicobacter pylori infection, smoking, histological type and tumor site in China," Asian Pacific Journal of Cancer Prevention, vol. 13, no. 6, pp. 2481-2484, 2012.

[14] A. Ogihara, S. Kikuchi, A. Hasegawa et al., "Relationship between Helicobacter pylori infection and smoking and drinking habits," Journal of Gastroenterology and Hepatology, vol. 15, no. 3, pp. 271-276, 2000.

[15] EUROGAST Study Group, "Epidemiology of and risk factors for Helicobacter pylori infection among 3194 asymptomatic subjects in 17 populations," Gut, vol. 34, no. 12, pp. 1672-1676, 1993.

[16] E. T. H. Fontham, B. Ruiz, A. Perez, F. Hunter, and P. Correa, "Determinants of Helicobacter pylori Infection and Chronic Gastritis," American Journal of Gastroenterology, vol. 90, no. 7, pp. 1094-1101, 1995.

[17] H. Brenner, D. Rothenbacher, G. Bode, and G. Adler, "Relation of smoking and alcohol and coffee consumption to active Helicobacter pylori infection: Cross sectional study," BMJ, vol. 315, no. 7121, pp. 1489-1492, 1997.

[18] L. C. Ddine, C. C. Ddine, C. C. R. Rodrigues, V. R. Kirsten, and E. Colpo, "Factors associated with chronic gastritis in patients with presence and absence of Helicobacter pylori," ABCD. Arquivos Brasileiros de Cirurgia Digestiva, vol. 25, no. 2, pp. 96-100, 2012.

[19] B. Salih, "Helicobacter pylori infection in developing countries: The burden for how long?" Saudi Journal of Gastroenterology, vol. 15, no. 3, pp. 201-207, 2009.

[20] Y. T. H. P. van Duynhoven and R. de Jonge, “Transmission of Helicobacter pylori: a role for food?" Bulletin of the World Health Organization, vol. 79, no. 5, pp. 455-460, 2001.

[21] A. G. Herrera, "Helicobacter pylori and food products: a public health problem," Methods in Molecular Biology, vol. 268, pp. 297-301, 2004.

[22] R. Shi, S. Xu, H. Zhang et al., "Prevalence and risk factors for helicobacter pylori infection in chinese populations," Helicobacter, vol. 13, no. 2, pp. 157-165, 2008.

[23] R. S. Mhaskar, I. Ricardo, A. Azliyati et al., "Assessment of risk factors of Helicobacter pylori infection and peptic ulcer disease," Journal of Global Infectious Diseases, vol. 5, no. 2, pp. 60-67, 2013. 


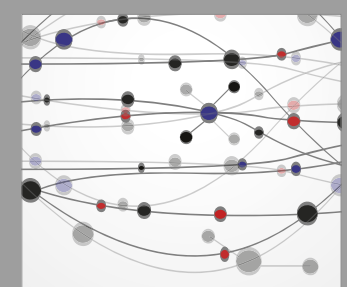

The Scientific World Journal
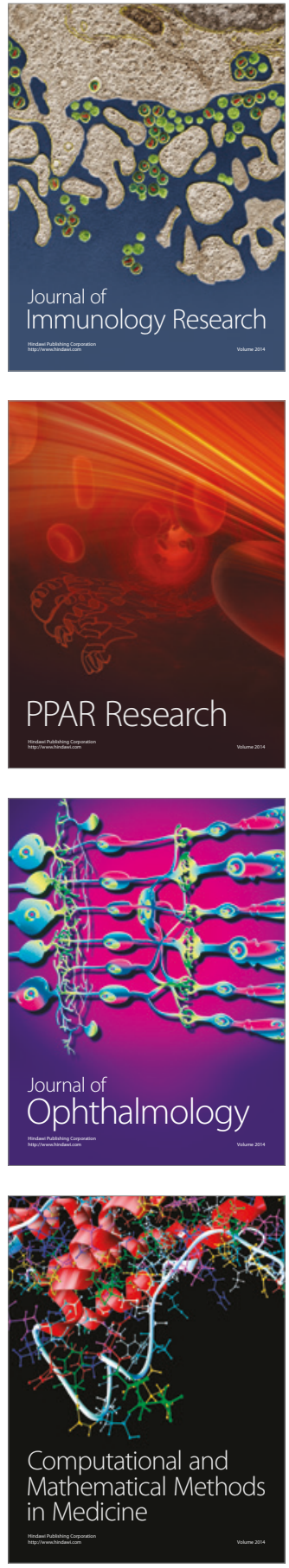

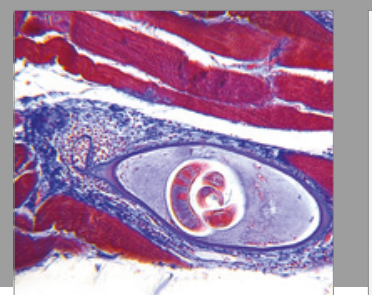

Gastroenterology Research and Practice
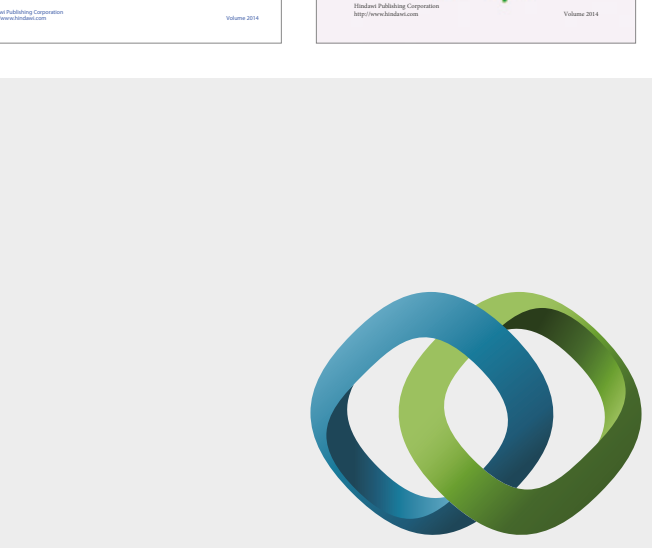

\section{Hindawi}

Submit your manuscripts at

https://www.hindawi.com
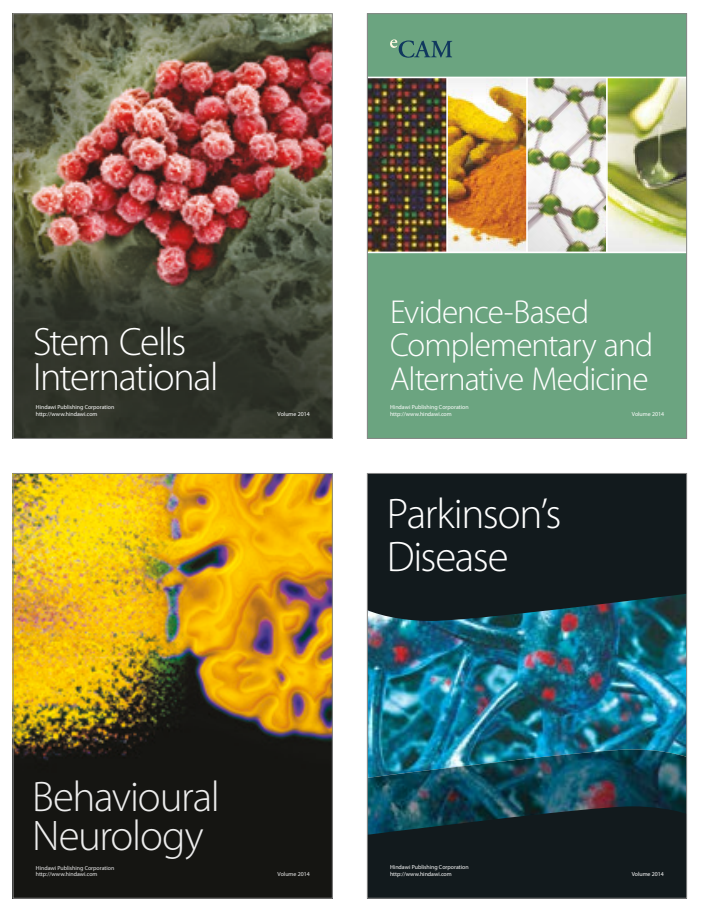
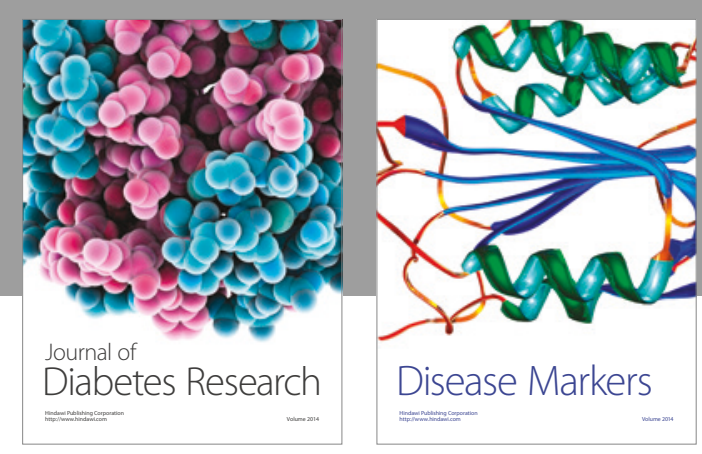

Disease Markers
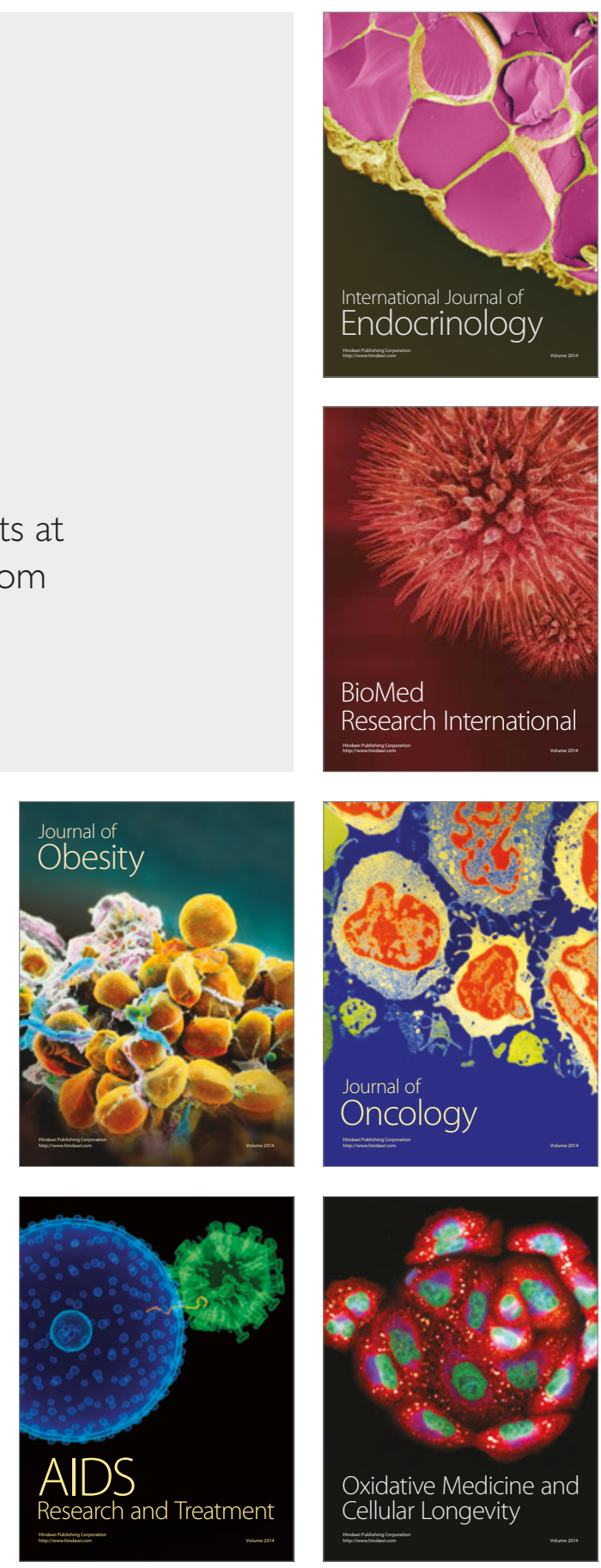